\title{
Value Crisis: Affective Organization of Personal Meanings
}

\author{
Hubert J. M. Hermans \\ University of Nijmegen, Nijmegen, The Netherlands
}

and

Piotr K. Oles

\section{Catholic University of Lublin, Lublin, Poland}

\begin{abstract}
The focus of this article is on the specific affective organization of the self in a value crisis. Whereas the self is conceptualized as an organized system of personal meanings, a value crisis is defined as a disorganization of this system. Personal meanings were investigated using a self-confrontation method that is sensitive to the affective properties of personal meanings and their organization into a composite whole. Three groups of students were compared, one high, one medium, and one low in value crisis. Results indicate that the high crisis group had a lower level of intensity of affect referring to self-enhancement, a lower intensity level of affect referring to contact and union with the other, and a lower level of positive affect in comparison with the other groups. In addition, negative meanings were more generalizing in the self of subjects in crisis, whereas positive meanings were more generalizing in the self system of those not in crisis. Moreover, people in crisis showed more discontinuity between their past and future than those not in crisis. Special emphasis was placed on the specific affective organization of subjects in crisis. Two idiographic case studies were presented to illustrate meaningful exceptions to the rule. It was concluded that value crisis is an "in-between state" involving the risk of disorganization of the self, but at the same time including opportunities for innovative self-development. ๑ 1996 Academic Press, Inc.
\end{abstract}

\section{VALUE CRISIS: AFFECTIVE ORGANIZATION OF PERSONAL MEANINGS}

Most psychological studies of human values are focused on differences in value preferences of groups or individuals or on the relationships between

Preparation of this article was supported in part by Grant ERB3510PL920261(653) from Community's Action for Cooperation in Science and Technology with Central and Eastern European Countries. We thank Sue Houston for her editorial remarks. Correspondence concerning this article should be addressed to Hubert J. M. Hermans, University of Nijmegen, Department of Clinical Psychology and Personality, P.O. Box 9104, 6500 HE Nijmegen, The Netherlands. E-mail: hhermans@ @ psych.kun.nl. 
values and other variables (e.g., Chin \& McClintock, 1993; Guastello, Rieke, Guastello, \& Billings, 1992; Maio \& Olson, 1994; Pfeiffer \& Cote, 1991; Prince, 1993; Shrum \& McCarty, 1992). Other researchers are more interested in the existence of general dimensions in the domain of values (e.g., Allport, 1937; Schwartz, 1992; Schwartz \& Bilsky, 1987). Despite such differences, a variety of authors, representing different theoretical and methodological traditions, emphasize the importance of a value system and valuing process for the self (Allport, 1937; Feather, 1975, 1988; Maslow, 1971; Rogers, 1964; Rokeach, 1973, 1985).

Whereas humanistically oriented authors (Maslow, 1971; Rogers, 1964) and cognitively oriented writers (Rokeach, 1973, 1985; Feather, 1975, 1988) have pointed to the general relevance of values for personality integration and well-being, we deal with more specific questions: What personal meanings are involved when we speak about values? How do people organize their selves when they experience a value crisis? What are the affective characteristics of the self when people are in a value crisis and, in particular, how is their well-being?

In addressing these questions, we present the several parts of this article in the following order: (a) description of valuation theory as a conceptual framework for the investigation of the affective characteristics of the personal meaning system; (b) a self-confrontation method based on valuation theory that allows for the investigation of personal meanings as an organized whole; and (c) an empirical comparison between groups of students high, medium, and low in value crisis, with attention to the organization of affective meanings and exceptions to the general findings. Finally, the relevance of the notion of affective organization will be discussed.

\section{VALUATION THEORY: PERSONAL VALUATION AS A PROCESS OF MEANING CONSTRUCTION}

A person, reflecting on his or her daily experiences, is involved in meaning construction, a process that is central to valuation theory (Hermans, 1987a,b, 1988, 1989; Hermans \& Hermans-Jansen, 1995). The view of the person in this theory is inspired by such philosophical-phenomenological thinkers as James (1890) and Merleau-Ponty (1945). The theory conceives of the self as an organized process of valuation. The "process" aspect refers to the historical nature of human experience and implies a spatio-temporal orientation. The individual lives in a present situation and is, from a specific point in space and time, oriented to past and future and to the surrounding world. The "organizational" aspect points to the fact that the individual not only orients successively to different parts of his or her spatio-temporal situation, but also brings those parts together in a story or self-narrative. In this story the several experiences are placed as parts in a composite whole, in which 
one experience is accorded a more influential place than another. In telling this story, the individual has the capacity for self-reflection, connecting the different experiences from different moments and periods with one another and organizing them as parts of a system of personal meanings.

The central concept, "valuation,' refers to any unit of meaning in which the events of a self-narrative are organized. It has a positive (pleasant), negative (unpleasant), or ambivalent connotation in the eyes of the individual. Personal valuations, as subjective constructions of personal experiences, refer to a broad range of phenomena such as: a dear memory, a pleasant activity, a disappointment in a contact with a significant other, a particular source of satisfaction, an unreachable ideal, etc. During different periods of one's life, different valuations may emerge because the individual's reference point is constantly changing. Through the act of self-reflective telling, these valuations are organized in a valuation system. This system can be seen as a composite made up of constant and changing valuations.

It is assumed that each valuation carries an affective connotation; that is, each valuation has a certain degree of personal involvement and reflects a particular set of feelings (a particular profile of affect). When we know which types of affect are characteristic of a particular valuation, we know something about the valuation itself. This also implies that the affective meaning of valuation cannot be separated from it.

\section{Manifest versus Latent Level of Organization}

The phenomenological richness of personal valuations, which may vary not only between individuals but also within a single individual across time and space, represents the manifest level of personality. At the latent level, however, a limited number of basic motives exist that are reflected in the affective component of the valuation system. Study of the affective component can therefore reveal which particular motive is active in a particular valuation and in the system as a whole. Two basic motives, in particular, have been taken into consideration to characterize the affective component of the valuation system: the striving for self-enhancement, or S motive (selfmaintenance and self-expansion), and the longing for contact and union with the other, or $\mathrm{O}$ motive (orientation toward other people and the surrounding world). This distinction concerning the basic duality of human experience has been present in the literature in the writings of various authors: Bakan (1966) viewed agency and communion as fundamental dynamic principles; Angyal (1965) relied on the concept of autonomy (or self-determination) and homonomy (or self-surrender); Klages (1948) considered Bindung (solidification) and Lösung (dissolution) to be two basic human motives; and McAdams (1985) has distinguished power and intimacy as basic motives in a narrative context. Recently, the dimensions of individualism-collectivism 
and idiocentricism-allocentrism, again suggesting the basic character of the $\mathrm{S}$ and $\mathrm{O}$ motives, have been extensively discussed and investigated (Triandis, Bontempo, Villareal, Asai, \& Lucca, 1988; Schwartz, 1990; Lau, 1992).

An example may clarify the relationship between the basic motives and the affective component of a valuation. When a person says "I finished my studies by working hard," this person may feel "pride", and "strength" in association with this valuation. It is supposed that the self-enhancement (S) motive is expressed in these feelings as part of the valuation. Similarly, when a person says, "I enjoyed the time that I spent with my friend in France," feelings of tenderness and intimacy may be experienced in close relation with this valuation. These feelings, then, are considered to be the affective expression of the motive for contact and union with the other $(\mathrm{O})$. It should be noted, however, that it is not our intention to exclude other theoretically well-founded motives which could also be incorporated into valuation theory.

In close correspondence with $\mathrm{S}$ and $\mathrm{O}$ feelings, well-being, in the form of the difference between positive and negative feelings, plays a central role in valuation theory. The rationale is that on their path toward fulfillment of basic motives, people meet obstacles. We are purposefully oriented to the world, but obstacles often prevent the achievement of our goals, resulting in negative feelings. On the other hand, when we achieve something, or succeed in overcoming obstacles and hindrances, we are rewarded with positive feelings. It is supposed that each valuation is associated with a pattern of positive and negative feelings so that the difference between both types of affect may give information about the extent to which our basic motives are gratified.

\section{Generalization and Idealization}

There are two concepts, generalization and idealization, that particularly represent the dynamic nature of valuation theory and play a central role in the methodology presented in the following section. The more a particular valuation generalizes as part of the system, the more it determines the "general feeling" of the person under consideration. When one asks a person how he or she feels in general, it is highly probable that particular experiences color this general feeling more than others. For example, if the person is living in a period of serious conflict with his or her spouse, there is a good chance that the feelings associated with this conflict are more likely to determine the person's general feelings in this period than, for example, the good contact this person experiences with his or her team mates. In other words, not all valuations are equally influential in the system. The more generalizing power a valuation has, the more influential the affective component of this valuation is in coloring the way the person generally feels in a certain period of life.

In a similar way, valuations may differ in the extent of idealization. The 
basic idea is that certain valuations fit more with the way an individual ideally would like to feel. Valuations that color the ideal feeling are often different from those that influence the general feeling. In particular, this is the case when people are actually going through a period in which they are faced with personal problems which affect their selves to a significant degree. Under such circumstances the ideal feeling typically has an affective modality that is in contrast to the affective modality of the general feeling.

\section{Value Crisis as a Disorganization of the Valuation System}

A tenet of valuation theory is that value crisis represents a transient or more enduring state of disorganization of the valuation system (Hermans \& Hermans-Jansen, 1995). It is supposed that as a result of critical life events or circumstances (biological, social, or environmental, see Brim \& Ryff, 1980) certain valuations referring to these events or circumstances become included in the valuation system and, depending on their impact, have a greater or lesser influence on the affective component of the self system. Important life events often represent new elements in a person's world and therefore require a reorganization of the valuation system. However, this reorganization may also fail. Sometimes a distressing event or series of events simply are not, or not yet, integrated into the valuation system, resulting in a disorganization of the valuation system as a whole. This disorganization is what we call a value crisis.

A value crisis has three implications. First, the valuations referring to important life events or situations are important parts of the system, and, consequently, their affective component has a strong generalizing influence in the system. Second, because critical events or situations leading to a crisis are often unscheduled (Neugarten, 1968; Glaser \& Strauss, 1966) and of a negative kind (e.g., failures at school, emotional problems with significant others, or death of a loved one), the valuations referring to these events or circumstances are associated with negative rather than positive affect and will have a low degree of idealization in the system. Third, the new valuations resulting from critical events or circumstances break the continuity of the valuation system, so that the valuations referring to the past, present, and future have different or even contrasting affective components (e.g., a person may be dissatisfied with the past, but is optimistic about the future). As various authors have suggested (Akhtar, 1984; Brooks-Gunn, Rock, \& Warren, 1989; Handel, 1987; Shmotkin, 1991), the continuity-discontinuity of personal meanings across changing time orientations is particularly relevant to wellbeing and development.

From a theoretical perspective, the distinction between the manifest and latent levels of functioning is crucial to understanding the organization of the valuation system. The myriad of possible valuations (different for different persons, and different for the same person in different periods of life) are 
studied from a limited amount of basic motives. The $\mathrm{S}$ motive is particularly relevant to the notion of value crisis, because a person whose self system is being influenced by distressing events or circumstances is expected to have a relatively large number of valuations with a low intensity level of affect referring to self-enhancement (McCrery, 1979; Oles, 1988; Rogers, 1964). Similarly, the $\mathrm{O}$ motive is relevant to value crisis, because a crisis is typically characterized by emotional problems in the contact with other people and with significant others in particular. Therefore, the valuations of people in value crisis are expected to be associated with a low intensity level of affect referring to contact and union (e.g., problems in the developmental tasks of intimacy and generativity, see Erikson, 1963; Farell \& Rosenberg, 1981; Kroger \& Haslett, 1991).

On the basis of the foregoing considerations, the following hypotheses are formulated:

1. Subjects in value crisis have more negative and fewer positive valuations than those not in crisis, and the difference between negative and positive valuations is higher among those in crisis.

2. The valuations from subjects in value crisis have a lower intensity level of affect referring to self-enhancement, a lower intensity level of affect referring to contact and union with the other, a lower intensity level of positive affect, and a higher intensity level of negative affect.

3 . For subjects in value crisis, negative valuations show a stronger generalization and a lower idealization than for those not in crisis, whereas positive valuations have a lower generalization and idealization for those in crisis than for those not in crisis.

4. The valuations referring to the past and the future are more discontinuous for those in crisis than for those not in crisis.

\section{THE SELF-CONFRONTATION METHOD AND VALUE CRISIS QUESTIONNAIRE}

For the study of the organized system of valuations, we used a selfconfrontation method, and for the assessment of value crisis we used a value crisis questionnaire.

\section{Self-Confrontation Method: Organization of the Valuation System}

The Self-Confrontation Method, based on valuation theory, has been devised to assess a person's valuation system with special attention to its affective organization (Hermans, 1987a,b, 1988, 1992; Hermans \& HermansJansen, 1995). The method contains two main parts: the construction of the valuations in an interview, and the connection of each valuation with a standard set of affect-denoting terms. This results in an affect matrix, filled in by the individual, in which each cell represents the extent to which specific 
affects (columns in the matrix) are characteristic of specific valuations (rows in the matrix).

Usually, the self-confrontation procedure implies that a series of open questions are presented to the participant to elicit the valuations. In this study the usual valuation interview was tailored to Allport's six value types. This enabled us to elicit the individual's personal response as a reaction to Allport's general values. With this purpose in mind, we posed the following questions (the area of theoretical issues may serve as an example of how valuations were elicited):

Theoretical issues: discovery of truth, cognition, knowledge: (a) How do you experience these issues in your life? (b) In what way are you personally engaged in these issues, or how do you realize them? (c) Do you find these issues important in your life in any other way? (The answers to these questions are personal valuations).

The questions for each issue are similar. The other issues were characterized as follows:

-Economic issues: utilities, practical affairs, wealth.

-Political issues: power, competition, struggle.

—Esthetic issues: beauty, form, harmony.

- Social issues: love of people, altruism.

— Religious issues: God, unity, excellence (see Allport, 1937, pp. 227231).

The questions are not devised as stimuli leading to quick responses, but as invitations to the subjects to reflect on their own lives, and to mention those matters which they consider as personally relevant. The subjects are encouraged to phrase the valuations in their own terms so that the formulation is as much as possible in agreement with the intended meaning. Within any set of questions the subject concentrates on that question which has the most evocative quality for him or her. It is possible that such a question will lead to more than one valuation. In order to have some impression of their temporal orientation, the subjects were also asked to formulate some valuations in relation to their own past and future as relevant to the issues mentioned above.

After the formulation of the valuations, a standard list of affect terms is offered to the subject. Concentrating on a single valuation, subjects are asked to indicate on a scale of $0-5$ to what extent they experience each affect in connection with the particular valuation. All statements are successively characterized using the same list of affect terms. The affect terms used in the present investigation are a list commonly used in valuation research (e.g., Hermans, Hermans-Jansen, \& Van Gilst, 1987; Hermans, 1987b) and is presented in Table 1.

The affect terms of Table 1 permit the calculation of a number of indices that reveal the organization of the valuation system from the perspective of 
TABLE 1

Affect Terms Used in the Self-Confrontation

Method

\begin{tabular}{ll}
\hline 1. Joy & 16. Solidarity \\
2. Powerlessness & 17. Self-confidence \\
3. Self-esteem & 18. Loneliness \\
4. Anxiety & 19. Inner warmth \\
5. Happiness & 20. Trust \\
6. Worry & 21. Inferiority \\
7. Strength & 22. Intimacy \\
8. Stress & 23. Security \\
9. Enjoyment & 24. Anger \\
10. Caring & 25. Despondency \\
11. Love & 26. Pride \\
12. Self-alienation & 27. Energy \\
13. Unhappiness & 28. Disappointment \\
14. Tenderness & 29. Inner calm \\
15. Guilt & 30. Freedom \\
\hline
\end{tabular}

the basic motives (Hermans, 1987a,b). The indices relevant to the present study are summarized below.

1. Index $\mathrm{S}$ is the sum total of four affect terms expressing self-enhancement: Nos. 3, 7, 17, and 26.

2. Index $\mathrm{O}$ is the sum total of four affect terms expressing contact and union with another: Nos. 10, 11, 14, and 22. (Note that the scores for the indices $\mathrm{S}$ and $\mathrm{O}$ range from 0 to 20 ).

3. Index $\mathrm{P}$ is the sum total of ten global positive (pleasant) affects: Nos. $1,5,9,16,19,20,23,27,29,30$.

4. Index $\mathrm{N}$ is the sum total of ten global negative (unpleasant) affects: Nos. 2, 4, 6, 8, 12, 15, 18, 21, 24, 28. (Note that the scores for the indices $\mathrm{P}$ and $\mathrm{N}$ range from 0 to 50 ).

5. For the assessment of the extent of generalization $(\mathrm{G})$ of a valuation within the system, the following question is asked at the end of the valuation construction phase: "How do I generally feel these days?', This question does not ask for a specific valuation but is devised to assess the "general feeling.' 'The person answers directly with the list of affect terms that was used for the characterization of the valuations. The product-moment correlation between the pattern of affect that belongs to a specific valuation and the pattern of affect that belongs to the general feeling is a measure of the extent of the generalization of this valuation. The more positive the correlation, the more this valuation is supposed to generalize within the system. For example, when a person is worrying all the time about his or her studies, it is expected that a valuation referring to this problem (e.g., "Wherever I 
am, I am always worrying about failing in my studies') has a high degree of generalization in the system. That is, the correlation between the affective profile belonging to this valuation and the affective profile belonging to the general feeling is expected to be high.

6. For the assessment of the idealization (I) of a valuation, the question is posed: "How would I like to feel?', The correlation between the affective profile belonging to a specific valuation and the affective profile belonging to the ideal feeling indicates the ideal quality of this valuation. The height of the correlation indicates the extent of the idealization of the valuation. The more positive the correlation, the higher the idealization. When a valuation has an affective profile that contrasts with the ideal feeling, this is expressed in a negative (minus) correlation. ( $\mathrm{G}$ and $\mathrm{I}$ represent the last rows in the matrix, see Appendix). Note that instead of the correlation coefficient (r), a distance metric (D) can be used. Index D has the advantage that it is sensitive to elevation differences between profiles, which seems particularly relevant in the case of the idealization index. Hermans (1987b) compared $r$ and D on several sets of valuations and found that the two measures showed a high degree of correspondence, expressed in a median Spearman rank correlation of -.93 (a high product-moment correlation coincides with a small distance). This finding, together with consistency in the use of index ( $\mathrm{r}$ instead of D) and economy of presentation (one index instead of two indices), led us to use $r$ as the index for both generalization and idealization. In doing so, we should be aware, however, that $r$ does not measure elevation differences, and that even when $\mathrm{r}$ and $\mathrm{D}$ are highly correlated, they do not capture identical information.

The first and second indices express two basic motives, $\mathrm{S}$ and $\mathrm{O}$. The third and fourth indices refer to positive and negative feelings that the subjects may experience when, on their way to gratify their basic motives, they are confronted with obstacles. For each valuation the $\mathrm{S}-\mathrm{O}$ and $\mathrm{P}-\mathrm{N}$ difference can be determined. The $\mathrm{S}-\mathrm{O}$ difference indicates the relative intensity of affect derived from the two basic motives. The $\mathrm{P}-\mathrm{N}$ difference indicates the well-being that a person experiences in relation to the specific valuation. (For reliability and validity data of $\mathrm{S}, \mathrm{O}, \mathrm{P}$, and $\mathrm{N}$ indices see Hermans, 1987b, p. 166, pp. 169-171; the self-investigation as described above, takes from about $1 \frac{1}{2}$ to $3 \mathrm{~h}$ for each person).

\section{Value Crisis Questionnaire}

Value crisis is measured by means of a Value Crisis Questionnaire (VCQ) (Oles, 1991). The instrument consists of 25 true-false items, which refer to different difficulties in the valuing process. The items are based on a conception of crisis as a state of tension and internal disorganization, accompanied by: (a) an inability to organize personal values into a coherent and hierarchi- 
cally ordered system (e.g., lack of value orientation, or unsolvable conflict between important values); (b) a sense of loss of values, usually caused by significant reevaluations (e.g., values that were significant in the past have lost their relevance for the present); (c) a lack of integration between cognitive, affective, and motivational aspects of the valuing process (e.g., difficulties in choosing between alternatives); and (d) a low sense of value realization (usually caused by inconsistencies between the value system and behavior or by unattainable goals or purposes). In a crisis, all or a few of these symptoms may be present, depending on the intensity of the crisis and the problems involved.

Some examples of items indicative of particular symptoms of value crisis are presented below:

1. I am able to define clearly what is most important in my life. (F)

2. I often have doubts concerning values and goals which I have chosen. (T)

3. I think that in general I choose the right goals and means. (F)

4. I feel that I have never realized anything substantial in my life. (T)

The VCQ was constructed and validated in a sample of university students. The validity of the VCQ was tested by correlating the global score with Crumbaugh and Maholick's (1981) Purpose in Life Test (PIL), on the assumption that lowered purpose in life is associated with value crisis as, for example, expressed in loss of values or lack of value realization (Baumeister, 1989). The correlation between the two scales was high $(r=.70, p<.001$, $n=218$ ), suggesting a clear convergence of the two tests. The internal consistency of the VCQ was .90 (Cronbach's alpha; $n=218$ ). The test-retest reliability was $.88(n=37)$ after a two week interval.

\section{Comparison of Valuation Approach and the Measurement of Value Crisis}

Some ideas are similar in the two approaches (assessment of valuations and measurement of value crisis). First, both are focused on valuing as an organized system: a structuring of parts into some composite whole is needed. Second, in both approaches valuing is seen as a cognitive-affective process. A valuation is regarded by Hermans (1987a) as an activity of meaning giving that has the character of a cognitive-affective process; value crisis (Oles, 1991) is considered as a general state of mind composed of cognitive and affective aspects.

There are also some differences between the two approaches. First, valuation theory offers a conceptual framework for the self as a composite whole, whereas the conception of value crisis gives a description of a single phenomenon. Second, according to valuation theory, self-reflection is considered an activity leading to the construction and reconstruction of personal meanings, whereas value crisis is a state arising from a transitory inability to construe an efficient meaning system. 


\section{Sample}

The participants in our study were 48 students from the Catholic University of Lublin, Poland (40 female and 8 male), 22-25 years old (there was no significant difference in mean age between the sexes). They were administered the Value Crisis Questionnaire and the Self-Confrontation Method, as described. The sample was divided into three groups according to the raw scores in VCQ: 14 Students (12 female, 2 male) who obtained high scores on the VCQ, that is, higher than $1 / 2 S D$ above the mean (high crisis group; $M=24.50, S D=8.28), 18$ students (14 female, 4 male) who obtained average scores on the VCQ, that is, lower than $1 / 2 S D$ above the mean and higher than $1 / 2 S D$ below the mean (medium crisis group; $M=8.00, S D=$ 1.97), and 16 students (14 female, 2 male) who obtained low scores on the VCQ, that is, lower than $1 / 2 S D$ below the mean (low crisis group; $M=2.38$, $S D=2.00$ ). Mean result in VCQ for the whole sample was $M=19.94, S D$ $=10.23$. In the following, the total number of valuations from each group were compared. (Note that the subjects were allowed to respond with more than one valuation for any issue, if they wanted).

\section{RESULTS: AFFECTIVE PROPERTIES OF VALUE CRISIS}

In order to test the first hypothesis, we compared the average number of valuations produced by three groups (see Table 2 ; some examples of valuations as typical of each group are presented in Table 5). These averages are based on the average number of valuations per subject across issues. As can be seen in Table 2, the high crisis group shows, in accordance with our expectations, a higher number of negative $(p<.05)$ and a lower number of positive valuations $(p<.05)$ in comparison with the low crisis group and the medium crisis group. In spite of these differences between the groups, there is an important observation to make from an organizational point of view: within the high crisis group there is no dominance of negative over positive valuations. Despite the existence of differences between the groups,

\section{TABLE 2}

Average Numbers of Positive and Negative Valuations for Groups High, Medium, and Low in Crisis

\begin{tabular}{|c|c|c|c|c|c|c|c|c|c|}
\hline \multirow[b]{2}{*}{ Valuations } & \multicolumn{2}{|c|}{ High Crisis } & \multicolumn{2}{|c|}{$\begin{array}{l}\text { Medium Cri- } \\
\text { sis }\end{array}$} & \multicolumn{2}{|c|}{ Low Crisis } & \multicolumn{2}{|c|}{ Differences } & \\
\hline & $M$ & $S D$ & $M$ & $S D$ & $M$ & $S D$ & $F(2,45)$ & $p<$ & \\
\hline Positive & 5.43 & 2.24 & 7.83 & 2.48 & 9.50 & 3.26 & 8.48 & .001 & $a b$ \\
\hline Negative & 3.93 & 2.62 & 1.72 & 1.67 & 1.38 & 1.59 & 7.32 & .005 & $a b$ \\
\hline Total & 9.36 & 2.73 & 9.89 & 3.12 & 11.13 & 3.40 & 1.30 & - & \\
\hline
\end{tabular}

Note. $\mathrm{a}=$ difference between groups high and low in crisis, $p<.05 ; \mathrm{b}=$ difference between groups high and medium in crisis, $p<.05$. 
TABLE 3

Means on the Affective Indices for High, Medium, and Low Crisis Group

\begin{tabular}{|c|c|c|c|c|c|c|c|c|c|}
\hline \multirow[b]{2}{*}{ Indices } & \multicolumn{2}{|c|}{ High Crisis } & \multicolumn{2}{|c|}{ Medium Crisis } & \multicolumn{2}{|c|}{ Low Crisis } & \multicolumn{2}{|c|}{ Differences } & \\
\hline & $M$ & $S D$ & $M$ & $S D$ & $M$ & $S D$ & $F(2,45)$ & $p<$ & \\
\hline S & 8.20 & 2.82 & 10.82 & 2.34 & 12.68 & 2.89 & 10.50 & .001 & $a b c$ \\
\hline $\mathrm{O}$ & 6.25 & 2.04 & 9.77 & 3.28 & 9.73 & 2.90 & 7.31 & .005 & $a b$ \\
\hline $\mathrm{P}$ & 20.44 & 6.18 & 28.55 & 5.32 & 32.99 & 4.61 & 20.83 & .001 & $a b c$ \\
\hline $\mathrm{N}$ & 15.20 & 4.75 & 13.43 & 6.76 & 10.16 & 5.57 & 2.92 & - & \\
\hline
\end{tabular}

Note. $\mathrm{a}=$ difference between groups High and Low in Crisis, $p<.05 ; \mathrm{b}=$ difference between groups High and Medium in Crisis, $p<.05 ; \mathrm{c}=$ difference between groups Medium and Low in Crisis, $p<.05 ; \mathrm{S}=$ affect referring to self-enhancement; $\mathrm{O}=$ affect referring to contact with the other; $\mathrm{P}=$ positive affect; $\mathrm{N}=$ negative affect.

there appears to be an almost equal ratio of positive and negative valuations within the high crisis group, whereas such a ratio is not found within the other two groups.

In order to test the second hypothesis, we compared the three groups (high, medium, and low) on the indices $\mathrm{S}, \mathrm{O}, \mathrm{P}$, and $\mathrm{N}$ (see Table 3 ) using a oneway analysis of variance. The means of the groups are based on averages across issues for each individual. For three of the four indices ( $\mathrm{S}, \mathrm{O}$, and $\mathrm{P}$ ), the differences between the groups are statistically significant, and in the expected direction: the high crisis group has a lower intensity level of affect referring to self-enhancement $(p<.05)$, a lower intensity level of affect referring to contact and union $(p<.05)$, and a lower intensity level of positive affect $(p<.05)$ than the medium and low crisis groups. Contrary to the second hypothesis, no significant differences between the groups were found for negative affect. This suggests that the high crisis group experiences less positive affect than the other groups, but not more negative affect. There is, moreover, another finding which does not fit our expectations: whereas the level of positive $(\mathrm{P})$ feelings exceeds the level of negative $(\mathrm{N})$ feelings to a large degree within the low crisis group and medium crisis group, a difference in the opposite direction is not found within the high crisis group. In the latter group, positive feelings are in fact slightly higher than negative feelings. Taken together, the results summarized in Table 3 indicate that the high crisis group is characterized not simply by a high intensity of negative valuations, but by a mixture of high positive and high negative intensity.

The results concerning the generalization and idealization are presented in Table 4. In agreement with the third hypothesis we find that, for the high crisis group, the positive valuations have a lower degree of generalization and the negative valuations a higher degree of generalization than for the groups low and medium in crisis ( $p<.05$ for both of the differences). Moreover, the positive valuations have, as expected, a lower degree of idealization 
TABLE 4

Mean Generalization and Idealization for Positive and Negative Valuations for Groups High, Medium, and Low in Crisis

\begin{tabular}{|c|c|c|c|c|c|c|c|c|c|}
\hline \multirow[b]{2}{*}{ Indices } & \multicolumn{2}{|c|}{ High Crisis } & \multicolumn{2}{|c|}{ Medium Crisis } & \multicolumn{2}{|c|}{ Low Crisis } & \multicolumn{2}{|c|}{ Differences } & \\
\hline & $M$ & $S D$ & $M$ & $S D$ & $M$ & $S D$ & $F$ & $p<$ & \\
\hline \multicolumn{5}{|c|}{ Positive valuations $(P>N)$} & \multicolumn{5}{|c|}{$F(2,45)$} \\
\hline $\mathrm{G}$ & .07 & .38 & .44 & .23 & .51 & .45 & 6.48 & .005 & $a b$ \\
\hline I & .44 & .22 & .64 & .14 & .74 & .13 & 12.26 & .001 & $a b$ \\
\hline \multicolumn{5}{|c|}{ Negative valuations $(P<N)$} & \multicolumn{5}{|c|}{$F(2,33)$} \\
\hline $\mathrm{G}$ & .30 & .29 & .04 & .24 & -.10 & .41 & 5.08 & .05 & $a b$ \\
\hline I & -.22 & .32 & -.30 & .22 & -.49 & .26 & 2.90 & - & \\
\hline
\end{tabular}

Note. $\mathrm{a}=$ difference between groups High and Low in Crisis, $p<.05 ; \mathrm{b}=$ difference between groups High and Medium in Crisis, $p<.05 ; \mathrm{G}=$ generalization, $\mathrm{I}=$ idealization.

in the high crisis group than in the low and medium crisis groups $(p<.05)$. In contrast to our expectations, however, there are no significant betweengroup differences in the extent of idealization for the negative valuations.

When we compare the results of Tables 3 and 4, we find that the high crisis group does not lack positive valuations (see Table 3), but these positive valuations do not generalize (mean correlation is .07, see Table 4 ). The opposite is true for the two other groups. The participants in these groups do not lack negative valuations (see Table 3 ) but these valuations do not generalize ( -.10 , and .04 for the low and medium group, respectively; see Table 4).

A more complex picture can be found when we select, in an idiographic analysis, the highest generalizing valuation from each individual system; that is, the one which has the highest correlation with the general feeling. The highest generalizing valuations from all participants, together with their affective patterns, are presented in Table 5 .

The advantage of this idiographic exploration is that we can compare the idiosyncratic content (formulation) of the separate valuations with their affective patterning. As Table 5 shows, various patterns are found in the different groups. For a classification of significant patterns, we follow a typology of valuations introduced by Hermans, Hermans-Jansen, and Van Gilst (1987). Typical valuations for the low and medium crisis groups are those representing a positive combination of high self-enhancement and high contact and union with the other (high $\mathrm{S}$, high $\mathrm{O}$, high $\mathrm{P}$, low $\mathrm{N}$; e.g., val. nos. $16,26,28,34$, and 37). By way of contrast, in the high crisis group one can see only a few such positive valuations (e.g., val. nos. 7 and 11). On the other hand, some valuations of the opposite type are found in this group, representing a negatively experienced combination of low self-enhancement and low contact and union with the other (low S, low O, low P, high N; 
TABLE 5

The Most Highly Generalizing Valuations Formulated by Students High, Medium, and Low in Value Crisis

\section{Valuation}

$\mathrm{S} \quad \mathrm{O}$

High crisis group

1. (F)** I would like to know everything clearly, in truth, so that normal interpersonal relationships become possible.

2. (F)** I want to know for sure that God exists, and acts in my life.

3. (F) I want to be needed by others.

4. (M)** It is very difficult for me to realize love for other people in my life.

5. (F) There is something in me which causes peoplealso dishonest ones - to ask me for help.

6. (F)** I like to dominate others but not to have any real power.

7. (F) — The first thing which inspires me to activity is a sense of esthetic form and beauty.

8. (F)** I don't need to fight, to be famous, or to have power; that is not for me.

9. (F)** I am very absorbed by religious questions, which disturb me a lot, and I try to find my individual way of joining my life and religion.

10. (F)* I want to be someone who has authority.

11. (F) Freedom-I want to act freely and to decide about my life. I am able to do that, being aware of limitations.

12. (F)** I withdraw from competition and struggle because it is a more suitable position: neither a winners nor a losers position is for me (I don't want to be last, and to win means that somebody lost).

13. (F) I am anxious that I will never gain enough knowledge, and I will never know and learn enough things to allow me to discover the truth.

14. (M) In everyday life I cannot find enough harmony and beauty, which I associate with real art.

Average crisis group

15. (M)* For me studying means to look for unreachable truth.

16. (F) Beauty of the world makes me rich and develops my sensitivity.

17. (F)** I like to smile at people and help them.

18. (F) Contact with other people is important to me: to be together, to make friends, to co-operate, to help.

19. (F) Looking for the truth is one of the most significant things I can do.

20. (F)* I want to notice and to understand the needs of people who are close to me.

$\begin{array}{rrrrr}2 & 0 & 1 & 32 & .83 \\ 7 & 0 & 10 & 32 & .69 \\ 16 & 3 & 32 & 0 & .93 \\ 5 & 5 & 17 & 21 & .62 \\ 5 & 6 & 15 & 28 & .63 \\ 3 & 0 & 6 & 4 & .45 \\ 16 & 17 & 43 & 2 & .73 \\ & & & & \\ 11 & 1 & 14 & 28 & .76 \\ & & & & \\ 10 & 7 & 10 & 30 & .48 \\ 16 & 5 & 33 & 10 & .61\end{array}$

$\begin{array}{lllll}16 & 11 & 37 & 17 & .52\end{array}$

$\begin{array}{lllll}8 & 0 & 6 & 28 & .64\end{array}$

$\begin{array}{lllll}0 & 0 & 1 & 41 & .70\end{array}$

$\begin{array}{lllll}13 & 18 & 41 & 2 & .83\end{array}$

$\begin{array}{lllll}13 & 7 & 27 & 24 & .46\end{array}$

$\begin{array}{lllll}14 & 17 & 41 & 8 & .87\end{array}$

$\begin{array}{lllll}10 & 13 & 34 & 3 & .44\end{array}$

$\begin{array}{lllll}8 & 10 & 29 & 8 & .62\end{array}$

$\begin{array}{lllll}11 & 8 & 32 & 12 & .65\end{array}$

$\begin{array}{llll}7 & 12 & 32 & 28\end{array}$ 
TABLE 5-Continued

$\begin{array}{llllll}\text { Valuation } & \mathrm{S} & \mathrm{O} & \mathrm{P} & \mathrm{N} & \mathrm{G}\end{array}$

21. (F)* I love Jack, who gives me support and a sense of safety.

22. (F) Faith in providence allows me to look forward to the future with optimism.

23. (F) The truth gives me a sense of direction of my life.

24. (F) I do my best not to waste my efforts in economic strivings.

$\begin{array}{lllll}12 & 19 & 37 & 19 & .85\end{array}$

25. (F) I am very involved in working on my thesis and I enjoy it.

26. (F) - I am fascinated by travel, curious about how other people live, watching landscapes, flora, fauna; however, I realize that I'll never be able to do it in a big way.

$\begin{array}{lllll}10 & 12 & 32 & 7 & .64\end{array}$

27. $(\mathrm{F})^{*}$ I love the harmony of nature which creates a peace in me, the same peace I find in music; unfortunately I haven't enough time for that.

28. (M) Truth is the most significant value in my life, it is a necessary point of reference and verification of things.

29. (F) My religious faith is of the greatest importance and value to me; thanks to my faith I am able to realize myself in this life, for I am not and I will never be perfect, and through prayer I meet the greatest Excellence and I appreciate that $\mathrm{He}$ always has time for me and wants to hear me.

30. (F) I often lack money.

31. (M) Religion and morality - in what way ought I to become better and better, how can I make my life meaningful and useful?

32. (M) I would like to gain inner harmony and to find such harmony in the environment.

Low crisis group

33. (F) The theoretical values I find in my study and in my own research activity.

34. (F) Music is everything, music fulfills and enriches my life.

$\begin{array}{lllll}5 & 14 & 37 & 11 & .71\end{array}$

$\begin{array}{lllll}18 & 20 & 47 & 6 & .95\end{array}$

$\begin{array}{lllll}8 & 9 & 32 & 6 & .83\end{array}$

$\begin{array}{lllll}1 & 2 & 2 & 18 & .19\end{array}$

$\begin{array}{lllll}10 & 11 & 26 & 20 & .75\end{array}$

$\begin{array}{lllll}11 & 15 & 33 & 7 & .82\end{array}$

$\begin{array}{lllll}14 & 11 & 38 & 1 & .89\end{array}$

$\begin{array}{lllll}15 & 15 & 41 & 11 & .86\end{array}$

35. (M) Power is attractive to me, because I like to dominate, yet simultaneously I am averse to power, because I am afraid of people who have power.

36. (F)* Love with my boy-friend is the most valuable and the most beautiful relationship I know.

37. (F) I love and I need other people, and they need me; when I am together with close friends or family I feel really happy.

38. (F) Love gave a beginning to my life; and I hope love will be with me to the end of my life. 
TABLE 5-Continued

\section{Valuation}

$\begin{array}{lllll}\mathrm{S} & \mathrm{O} & \mathrm{P} & \mathrm{N} & \mathrm{G}\end{array}$

39. (F) Utility of my work - this is what I like, to see the fruits of my endeavors.

40. (F) I am often stubborn, I remember insults for a long time.

41. (F) I like to seek the truth especially when it leads me to a defined goal, like better relationships with others.

42. (F) I like to give and to get practical gifts.

43. (F) I love music.

44. (M) I study psychology, I want to understand other people and myself better.

45. (F) I try to be altruistic, and in doing so I influence others to reflect on themselves.

46. (F) God is the source and goal of my life.

$\begin{array}{rrrr}17 & 12 & 35 & 20 \\ 1 & 0 & 7 & 29\end{array}$

47. (F) I am afraid of fighting and dishonest competition, because it causes hate and disaster in a group or society.

48. (F) God's love penetrates my everyday life, every moment of it.

$\begin{array}{rrrrr}15 & 16 & 41 & 9 & .80 \\ 8 & 4 & 29 & 5 & .73 \\ 14 & 15 & 41 & 1 & .88 \\ & & & & \\ 14 & 7 & 27 & 22 & .37 \\ & & & & \\ 16 & 12 & 42 & 6 & .90 \\ 20 & 19 & 49 & 9 & .90 \\ & & & & \\ 1 & 0 & 0 & 37 & .46 \\ 16 & 12 & 40 & 4 & .82\end{array}$

Note. $\mathrm{S}=$ affect referring to self-enhancement; $\mathrm{O}=$ affect referring to contact with the other; $\mathrm{P}=$ positive affect; $\mathrm{N}=$ negative affect; $\mathrm{G}=$ general feeling; $\mathrm{F}$-female; $\mathrm{M}-$ male. The valuations are ordered according to the results in VCQ. By ** are signed cases which reveal discontinuity between valuations related to the past and future; by * are signed cases which reveal continuity as well as discontinuity; - lack of valuations related to the past and future.

e.g., val. nos. 1 and 13). The affective meaning of such valuations typically expresses a combination of powerlessness (low $\mathrm{S}$ ) and isolation (low $\mathrm{O}$ ).

Another, less obvious type of valuation which appears in the high crisis group represents a so-called "negative self-enhancement" (high $\mathrm{S}$, low $\mathrm{O}$, low P, high N; e.g., val. nos. 2, 8, and 12). This type of valuation was found in an earlier study to be typical of anger and opposition (Hermans, 1992). As the affective pattern of this type indicates, it is associated with a high degree of $\mathrm{S}$ affect in combination with a high degree of $\mathrm{N}$ affect, and represents, as such, a certain amount of strength combined with negative affect (e.g., as one can feel when one is angry about something). It suggests that some people in the high crisis group are not simply powerless and isolated (as indicated by the combination of low $\mathrm{S}$, low $\mathrm{O}$, low $\mathrm{P}$, and high $\mathrm{N}$ ), but also have a tendency to revolt.

Although in the low crisis group and medium crisis group there are many more high $\mathrm{S}$, high $\mathrm{O}$, high $\mathrm{P}$, low $\mathrm{N}$ valuations (e.g., val. nos. 16, $26,28,34,37$, and 38), and more high $\mathrm{S}$, low $\mathrm{O}$, high $\mathrm{P}$, low $\mathrm{N}$ valuations (e.g., val. nos. 23, 25, and 44), representing positively experienced self- 
enhancement, than in the high crisis group, some of these positive and highly generalizing valuations are also found in the high crisis group (val. nos. 3, $7,10,11$, and 14). This variation suggests that the psychological picture of a person high in value crisis is not a uniform, but rather a multifaceted one. Therefore, conclusions about self-organization in value crisis, which are based on group comparisons, are only to a limited degree interpretable on the level of individual findings.

Finally, in order to test the fourth hypothesis, we analyzed our data according to the dimension of continuity vs. discontinuity. Therefore, we compared the valuations related to the past and future within each subject, with the purpose of assessing the continuity vs discontinuity of the valuations. There is "continuity" when a valuation referring to the past represents the same type as a valuation referring to the future. There is "discontinuity" when valuations referring to the past and those referring to the future represent different types. Those valuations that are characterized by discontinuity or by the simultaneous existence of discontinuity and continuity are marked in Table 5 (note that the subjects were allowed to formulate more than one valuation relating to the past or future). For all students in the low crisis group, except one, we find only continuity. In the medium crisis group we also find much more continuity than discontinuity, whereas for students in the high crisis group there is much more discontinuity. In only one case (no. 13) do we find "negative continuity," that is, the valuations related to past and future are both negative (low $\mathrm{S}$, low $\mathrm{O}$, low $\mathrm{P}$, high $\mathrm{N}$ ).

In order to get a more complete picture of our findings, we performed an additional idiographic analysis (for the complementary relationship between nomothetic and idiographic research, see Allport, 1962; Hermans, 1988, and Thomae, 1968/1988). We should note that there are some students high in value crisis who do not reveal discontinuity of personal meanings, nor negative valuations strongly generalizing in the system (consider val. nos. 3, 7, 11,14 in Table 5). Why are they diagnosed as being in value crisis? Is value crisis possible without any clear sign of problem in the most generalizing valuations in the self-system? Similarly, in the low crisis group we find two students revealing negative valuations strongly generalizing in the system (consider val. nos. 40 and 47). One can ask, why do people who are not in a period of value crisis have a negative well-being? Looking for answers to such questions, we discuss here the two most exceptional cases in our study.

The first case is selected from the high crisis group and is represented by valuation no. 3 in Table 5. This subject, Jane, was selected as the participant in the high crisis group who deviated most: she obtained the third highest score in the VCQ, but, contrary to our expectation, her most generalizing valuation is not negative but positive, and, moreover, she shows no discontinuity. All valuations from this student are presented in Table 6.

Referring to the affective pattern of Jane's general feeling, we suspect 
TABLE 6

Case 3. Subject High in Value Crisis: Jane's Valuations and Indices

Indices

Nos.

Valuations

$\mathrm{S} \quad \mathrm{O}$

1. I know that I should learn more, but I often don't have enough energy to do so.

2. When I have money I enjoy spending it; when

I lack money I try to be more thrifty.

3. I hate ugliness and I look for beauty anywhere it can be found.

4. To be open to others - which I find difficultgives me real satisfaction and a sense of unity with the world.

5. I don't like it when somebody manipulates me, or uses their superiority over me.

6. Perfection means for me to live in harmony with myself, not to harm other people, with God as my centre of support.

7. In the past, religion was the most important thing for me.

8. I want to be needed by others.

$$
4
$$$$
215
$$

19

.00

.22

$\begin{array}{rrrrrr}0 & 0 & 5 & 0 & .41 & .52 \\ 0 & 6 & 25 & 0 & .47 & .55\end{array}$

52

55

\begin{tabular}{rrrrrr}
13 & 14 & 41 & 10 & .75 & .56 \\
4 & 0 & 2 & 4 & .17 & -.03 \\
& & & & & \\
7 & 0 & 17 & 10 & .36 & .48 \\
& & & & & \\
10 & 8 & 34 & 0 & .82 & .58 \\
16 & 3 & 32 & 0 & .93 & .52 \\
15 & 5 & 33 & 0 & - & .55 \\
4 & 4 & 30 & 6 & .55 & - \\
\hline
\end{tabular}

General feeling

Ideal feeling

Note. $\mathrm{S}=$ affect referring to self-enhancement; $\mathrm{O}=$ affect referring to contact with the other; $\mathrm{P}=$ positive affect; $\mathrm{N}=$ negative affect; $\mathrm{G}=$ generalization; $\mathrm{I}=$ idealization.

that she is primarily oriented toward the realization of her self-enhancement motive $(\mathrm{S}>\mathrm{O})$. However, on the explored areas of her present personal experience (val. nos. 1-6), she cannot find much satisfaction in her life (with the exception of val. no. 4). The most highly generalizing valuations are the ones which refer to the past (val. no. 7) and to the future (val. no. 8). This suggests that her general feeling is not strongly supported by the valuations referring to her present situation. That is, she is only able to fulfill her basic motives to a limited degree and, therefore, she turns back to the positive experiences in her past and finds some compensation in her wishes for the future.

The second case is selected from the low crisis group and is represented by valuation 47 in Table 5. This participant, Joan, obtained the second lowest score in the VCQ. Her highest generalizing valuation, however, is very negative, which is atypical of the low crisis group. All her valuations are presented in Table 7.

At a first glance, Joan's system reveals some very positive valuations which have minus correlations with the general feeling (val. nos. 1, 3, 4, 7, 8,9 , and 10). In spite of the many positive valuations with high levels of selfenhancement and contact and union, Joan's general feeling is very negative. 
TABLE 7

Case 47. Subject Low in Value Crisis: Joan's Valuations and Indices

Indices

Nos.

Valuations

$\begin{array}{llllll}\mathrm{S} & \mathrm{O} & \mathrm{P} & \mathrm{N} & \mathrm{G}\end{array}$

I

1. Gaining knowledge thanks to my studies I can better understand the other person.

2. Wealth makes a person insensitive to the needs of other people.

3. The beauty of nature makes me happy.

4. When I love I feel satisfied and happy.

5. Power, conceived as superiority over others, destroys relationships between people.

$\begin{array}{rrrrrr}12 & 9 & 35 & 7 & -.23 & .82 \\ 1 & 2 & 3 & 34 & .43 & -.74 \\ 12 & 14 & 42 & 6 & -.52 & .89 \\ 17 & 17 & 45 & 2 & -.46 & .95 \\ & & & & & \\ 9 & 0 & 1 & 43 & .43 & -.83 \\ & & & & & \\ 1 & 0 & 0 & 37 & .46 & -.78 \\ 14 & 19 & 47 & 1 & -.46 & .93 \\ & & & & & .94 \\ 14 & 20 & 50 & 2 & -.47 & .94 \\ 14 & 17 & 47 & 3 & -.44 & \end{array}$

10. God, unity, love, and knowledge will make me able to discover the richness of others, and of myself.

$\begin{array}{lllll}15 & 18 & 44 & 7 & -.43\end{array}$

$11 *$ I feel deep sorrow after my grandmother's death, she was very close to me; the death set her free from suffering, but I missed being with her during her last hours.

General feeling

Ideal feeling

$\begin{array}{rrrrcc}4 & 4 & 8 & 30 & 1.00 & -.32 \\ 4 & 4 & 8 & 30 & - & -.32 \\ 10 & 14 & 43 & 0 & -.32 & -\end{array}$

Note. $\mathrm{S}=$ affect referring to self-enhancement; $\mathrm{O}=$ affect referring to contact with the other; $\mathrm{P}=$ positive affect; $\mathrm{N}=$ negative affect; $\mathrm{G}=$ generalization; $\mathrm{I}=$ idealization.

* Participants were allowed to add valuation(s), if there was something very important in their life which was not covered by the valuations generated on the basis of the standard sets of questions.

Apparently, her general feeling has the same affective pattern as a recent painful experience reported in valuation no. 11. Thus, negative well-being is caused by a stressful life event, which at the time of investigation had a strong generalizing power. This experience was so influential that the other, more positive meanings were pushed into the background of the system. In other words, negative well-being may be caused by reasons other than value crisis and does not necessarily imply an emphasis of negative valuations in the system as a whole. 


\section{DISCUSSION}

There are two ways of studying the affective properties of value crisis. The first is to perform a comparative study between groups in order to assess the differences in the separate variables included in the study. The second is to examine the organization of the variables within a person or a group of persons. Let us consider the results of our study from both perspectives.

When we compare the participants of our study on separate variables, the results can be summarized thus: the group high in value crisis had more negative and less positive valuations than the groups medium and low in value crisis. Moreover, the high crisis group had a low intensity level of affect referring to self-enhancement, a low intensity level of affect referring to contact and union with other people, and a low intensity level of positive affect, in comparison with the groups low or medium in value crisis. The extent of generalization also showed significant differences: In the high crisis group negative valuations were most generalizing, whereas in the low crisis group positive valuations had the most generalizing influence. So far, the results are in accordance with our expectations and, moreover, the results seem fairly intuitive. When, on the other hand, we consider the results from an organizational point of view, we may ask how people in a period of value crisis organize their selves. When the question is posed this way, the difference between separate variables is not of prime importance but rather the patterning of variables is what first draws our attention. When we consider our study from this perspective, the results represent a higher level of complexity and are less intuitive. Conceiving value crisis as an organized process of valuation, we are particularly interested in the way in which subjects high in value crisis order their personal meanings. We found that for subjects high in value crisis, the level of positive affect exceeded the level of negative affect to some degree, although the valuations associated with this positive affect did not generalize in the system.

When we focused on the valuations that are most generalizing within the system, we found that the high crisis group includes a variety of types of valuations in the system, some of which were positive, others negative. This variation was also revealed when we examined, in an idiographic analysis, the valuations of our most exceptional cases. Taken together, these results suggest that the psychological pictures of the participants in our study are different when considering them in a between system comparison than when studying them in a within system analysis. The within system comparison suggests that participants high in value crisis have a specific way of organizing their selves. They have the capacity to include a broad range of experiences, but are unable or unwilling to let one type of valuation dominate the system as a whole. They have a mixture of contrasting types of experiences, without giving one of these types a dominating position in the organized 
self-system. One may look at this type of organization in different ways. On the positive side, the high crisis group has broadened their horizon which opens new possibilities for growth and development in a multitude of directions. On the negative side, this way of organizing the self may result in a sense of confusion and loss of direction that Erikson (1959) and others (e.g., Cote \& Levine, 1987, 1988) have so well described.

The organization of the multifaceted selves of the high crisis group resembles, to some degree, the so-called self-schemas in mildly depressed patients and in normal people with a depressive mood (Alloy \& Lipman, 1992; Kuiper, Olinger, \& Swallow, 1987; Sutton, Teasdale, \& Broadbent, 1988). Their self-schema consists of both positive and negative aspects of the self and is weakly consolidated in contrast with normal and deeply depressed people whose self-schema are strongly consolidated and consist of positive or negative elements. As Dance and Kuiper (1987) suggest, mild depressives have begun to include negative information in their view of self and are perhaps questioning the applicability of existing positive features. These processes produce the inefficiency and inconsistency of self-referent processing, as similarly observed in value crisis.

The conclusion, as formulated above, is in line with the results on the continuity/discontinuity issue. The finding that some people high in value crisis refer to different types of valuation in their past as compared to their future is again an observation that touches the organizational feature of the self-system. Taken together with the other findings, this way of organizing the self suggests that the participants high in value crisis are searching for a positive direction in life, without being very sure of the right direction. Whereas they typically refer to negative valuations in their past or present, they refer to positive valuations in their future. This means that they do not find themselves in a situation of hopelessness or helplessness, but rather in a state of tension and uncertainty that marks an experiential field between negative and positive experiences. It is relevant to add that the tendency to assess future aspects of self more optimistically than past and present ones is typical of young adults (Ryff, 1991). Simultaneously, negative possible selves, feared or undesired ones, in combination with positive selves create a motivation to realize desired ones, and may work in developmentally beneficial ways (Oyserman \& Markus, 1990).

Although the existence of an experiential field between positive and negative experience may work out in beneficial ways, one should not be blind to the costs. The problematic aspects of this kind of self-organization were emphasized by Campbell (1990), who examined the association between affective and knowledge components of the self. She found that the selfconcept of low self-esteem subjects (comparable with our high crisis subjects) was characterized by less clarity or certainty than that of high selfesteem subjects (comparable with our low crisis subjects). When we inspect 
the content (formulation) of the highest generalizing valuations in the high crisis group (Table 5), we see that some of the subjects in this group explicitly refer to a need for clarity or certainty (e.g., "I would like to know everything clearly. ...,' see valuation 1, and "I want to know for sure that God exists. .." see valuation 2). Such valuations were not found in the low and middle crisis groups. These observations, in combination with the existence of discontinuity between past and future, suggest that people in crisis are searching for new directions but are, at the same time, plagued by a lack of clarity and certainty about themselves and the world.

Given their extended field of experience, it is too simple to consider people in a period of value crisis as dysfunctional or even as being in a transitory state of dysfunction. Given the tensions brought about by the apparent uncertainty and unclarity, it is also too simple to see them as functioning in efficient and productive ways. Value crisis is rather a period of "new possibilities with considerable mental risks." In Chinese, the word "crisis" has two meanings: "danger" and "opportunity.', This is precisely what a value crisis means: it is an "in-between state" that involves the risk of disorganization of personality functioning, but at the same time offers opportunities for innovative self-development. 


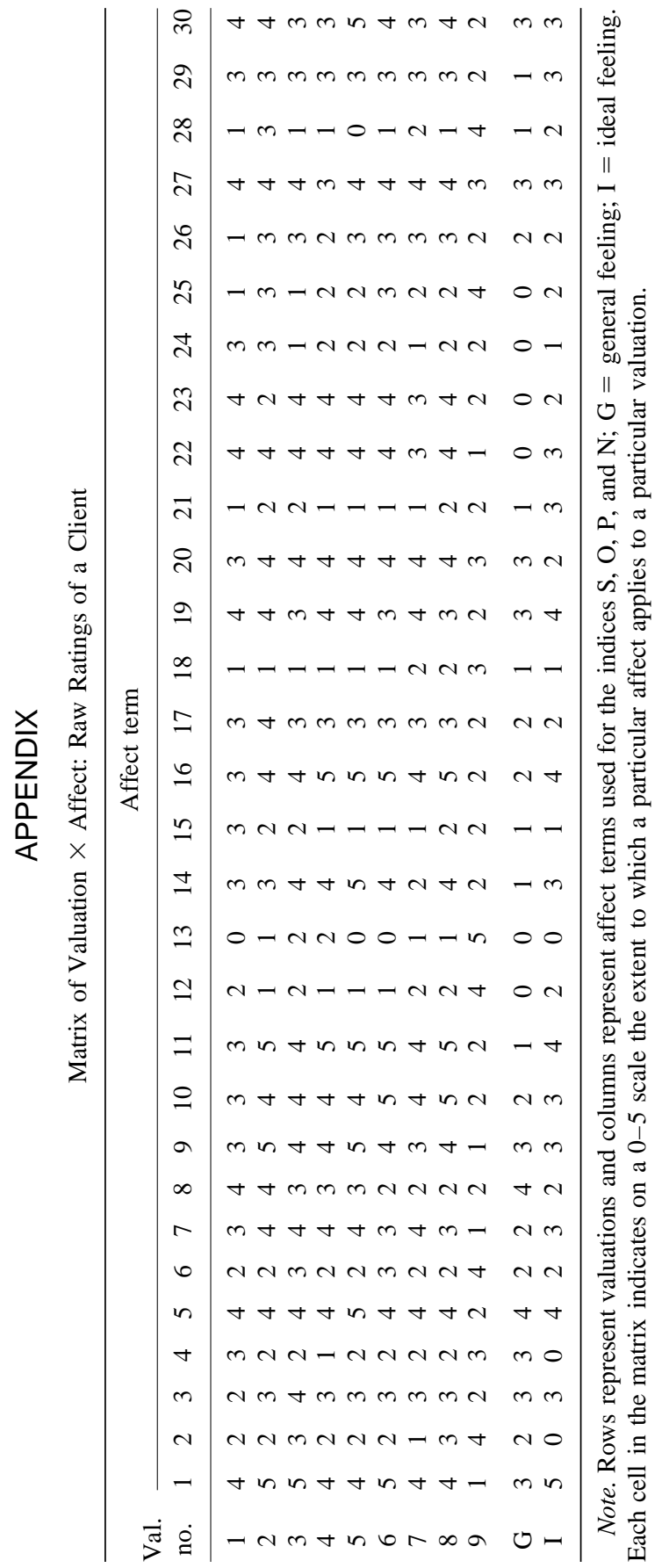




\section{REFERENCES}

Akhtar, S. (1984). The syndrome of identity diffusion. American Journal of Psychiatry, 14, $1381-1385$.

Alloy, L. B., \& Lipman, A. J. (1992). Depression and selection of positive and negative social feedback: Motivated preference or cognitive balance? Journal of Abnormal Psychology, 101, 310-313.

Allport, G. W. (1937). Personality: A psychological interpretation. New York: Holt.

Allport, G. W. (1962). The general and the unique in psychological science. Journal of Personality, 30, 405-422.

Angyal, A. (1965). Neurosis and treatment: A holistic theory. New York: Wiley.

Bakan, D. (1966). The duality of human existence. Chicago: Rand McNally.

Baumeister, R. F. (1989). The problems of life's meaning. In D. M. Buss \& N. Cantor (Eds.), Personality psychology: Recent trends and emerging directions (pp. 138-148). New York: Springer-Verlag.

Brim, O. G., Jr., \& Ryff, C. D. (1980). On the properties of life events. In P. B. Baltes \& O. G. Brim, Jr. (Eds.), Life-span development and behavior (Vol. 3, pp. 367-388). New York: Academic Press.

Brooks-Gunn, J., Rock, D., \& Warren, M. P. (1989). Comparability of constructs across the adolescent years. Developmental Psychology, 25, 51-60.

Campbell, J. D. (1990). Self-esteem and clarity of the self-concept. Journal of Personality and Social Psychology, 59, 538-549.

Chin, M. G., \& McClintock, C. G. (1993). The effects of intergroup discrimination and social values on level of self-esteem in the minimal group paradigm. European Journal of Social Psychology, 23, 63-75.

Cote, J. E., \& Levine, C. (1987). A formulation of Erikson's theory of ego identity formation. Developmental Review, 7, 273-325.

Cote, J. E., \& Levine, C. (1988). The relationship between ego identity status and Erikson's notions of institutionalized moratoria, value orientation stage, and ego dominance. Journal of Youth and Adolescence, 17, 81-99.

Crumbaugh, J. C., \& Maholick, L. T. (1981). Manual and instruction for the Purpose in Life Test. Munster: Psychometric Affiliates.

Dance, K. A., \& Kuiper, N. A. (1987). Self-schemata, social roles, and a self-worth contingency model of depression. Motivation and Emotion, 11, 251-268.

Erikson, E. H. (1959). Identity and the life cycle. New York: International Univ. Press.

Erikson, E. H. (1963). Childhood and society. New York: Norton.

Farell, M. P., \& Rosenberg, S. D. (1981). Men at midlife. Boston: Auburn House.

Feather, N. T. (1975). Values in education and society. New York: Free Press.

Feather, N. T. (1988). The meaning and importance of values: Research with the Rokeach Value Survey. Australian Journal of Psychology, 40, 377-390.

Glaser, B. G., \& Strauss, A. L. (1966). Awareness of dying. Chicago: Aldine.

Guastello, S. J., Rieke, M. L., Guastello, D. D., \& Billings, S. W. (1992). A study of cynicism, personality, and work values. Journal of Psychology, 126, 37-48.

Handel, A. (1987). Personal theories about life-span development of one's self in autobiographical self-presentations of adults. Human Development, 30, 83-98.

Hermans, H. J. M. (1987a). Self as an organized system of valuations: Toward a dialogue with the person. Journal of Counseling Psychology, 34, 10-19.

Hermans, H. J. M. (1987b). The dream in the process of valuation: A method of investigation. Journal of Personality and Social Psychology, 53, 163-175.

Hermans, H. J. M. (1988). On the integration of idiographic and nomothetic research method in the study of personal meaning. Journal of Personality, 56, 785-812.

Hermans, H. J. M. (1989). The meaning of life as an organized process. Psychotherapy, 26, $11-22$. 
Hermans, H. J. M. (1992). Unhappy self-esteem: A meaningful exception to the rule. The Journal of Psychology, 126, 555-570.

Hermans, H. J. M., \& Hermans-Jansen, E. (1995). Self-narratives: The construction of meaning in psychotherapy. New York: Guilford Press.

Hermans, H. J. M., Hermans-Jansen, E., \& Van Gilst, W. (1987). The fugit amor experience in the process of valuation: A self-confrontation with an unreachable other. British Journal of Psychology, 78, 465-481.

James, W. (1890). The principles of psychology (Vol. 1). London: MacMillan.

Klages, L. (1948). Charakterkunde [Characterology]. Zürich: Hirzel.

Kroger, J., \& Haslett, S. J. (1991). A comparison of ego identity status transition pathways and change rates across five identity domains. International Journal of Aging and Human Development, 32, 303-330.

Kuiper, N. A., Olinger, L. J., \& Swallow, S. R. (1987). Dysfunctional attitudes, mild depression, view of self, self-consciousness, and social perceptions. Motivation and Emotion, 11, 379-401.

Lau, S. (1992). Collectivism's individualism: Value preference, personal control, and the desire for freedom among Chinese in Mainland China, Hong Kong, and Singapore. Personality and Individual Differences, 13, 361-366.

Maio, G. R., \& Olson, J. M. (1994). Value-attitude-behaviour relationships: The moderating role of attitude functions. British Journal of Social Psychology, 33, 301-312.

Maslow, A. H. (1971). Psychological data and value theory. In A. H. Maslow (Ed.), New knowledge in human values (Vol. 2, pp. 119-136). Chicago: Gatteway.

McAdams, D. P. (1985). Power, intimacy, and the life story: Personological inquiries into identity. Chicago: Dorsey Press (reprinted by Guilford Press).

McCrery, J. R. (1979). Contributors to value system stability. Dissertation Abstracts International, 39(9-B), 4587.

Merleau-Ponty, M. (1945). Phénoménologie de la perception (Phenomenology of perception). Paris: Gallimard.

Neugarten, B. L. (1968). Adult personality: Toward a psychology of the life cycle. In B. L. Neugarten (Ed.), Middle age and aging (pp. 137-147). Chicago: Univ. of Chicago Press.

Oles, P. K. (1988). Self-concept and value-crisis. In A. Biela \& Z. Uchnast (Eds.), Problems with the self in psychology (pp. 142-148). Selected papers presented during the symposium in Kazimierz, Poland. Lublin: KUL.

Oles, P. K. (1991). Value crisis: Measurement and personality correlates. Polish Psychological Bulletin, 22, 53-62.

Oyserman, D., \& Markus, H. (1990). Possible selves in balance: Implications for delinquency. Journal of Social Issues, 46, 141-157.

Pfeiffer, M., \& Cote, J. E. (1991). Inglehart's silent revolution thesis: An examination of lifecycle effects in the acquisition of postmaterialist values. Social Behavior and Personality, 19, 223-235.

Prince, M. (1993). Self-concept, money beliefs, and values. Journal of Economic Psychology, 14, 161-173.

Rogers, C. R. (1964). Toward modern approach to values: The valuing process in the mature person. Journal of Abnormal and Social Psychology, 68, 160-167.

Rokeach, M. (1973). The nature of human values. New York: Free Press.

Rokeach, M. (1985). Including change and stability in belief system and personality structures. Journal of Social Issues, 41, 153-171.

Ryff, C. D. (1991). Possible selves in adulthood and old age: A tale of shifting horizons. Psychology and Aging, 6, 286-295.

Schwartz, S. H. (1990). Individualism-collectivism: Critique and proposed refinements. Journal of Cross-Cultural Psychology, 21, 139-157.

Schwartz, S. H. (1992). Universals in the content and structure of values: Theoretical advances 
and empirical tests in 20 countries. Advances in Experimental Social Psychology, 25, 165 .

Schwartz, S. H., \& Bilsky, W. (1987). Toward a universal psychological structure of human values. Journal of Personality and Social Psychology, 53, 550-562.

Shmotkin, D. (1991). The role of time orientation in life satisfaction across the life span. Journal of Gerontology, 46, 243-250.

Shrum, L. J., \& McCarty, J. A. (1992). Individual differences in differentiation in the rating of personal values: The role of private self-consciousness. Personality and Social Psychology Bulletin, 18, 223-230.

Sutton, L. J., Teasdale, J. D., \& Broadbent, D. E. (1988). Negative self-schema: The effects of induced depressed mood. British Journal of Clinical Psychology, 27, 188-190.

Thomae, H. (1968). Das Individuum und Seine Welt (The individual and his world). (2nd. ed., 1988). Göttingen: Hogrefe.

Triandis, H. C., Bontempo, R., Villareal, M. J., Asai, M., \& Lucca, N. (1988). Individualism and collectivism: Cross-cultural perspectives on self-ingroup relationships. Journal of Personality and Social Psychology, 54, 323-338. 